\title{
A pandemia e o desmonte do Estado
}

| ${ }^{1}$ Jane Araujo Russo |

1 Instituto de Medicina Social, Universidade do Estado do Rio de Janeiro-RJ, Brasil (jane.russo@gmail.com). ORCID: 0000-0002-4383-334X

DOI: http://dx.doi.org/10.1590/S0103-73312020300300

Em julho de 2020, o país chegou ao seu quinto mês imerso na epidemia de Covid-19. De início lenta no começo do mês de março, com alguns contágios e mortes em São Paulo e Rio de Janeiro - aparentemente importados por pessoas que chegavam de viagens do exterior - a epidemia se espalhou muito rapidamente, atingindo também o Norte e o Nordeste do país, revelando a fragilidade do sistema público de saúde nesses locais, em especial Manaus. Quando escrevo este editorial, o Sul e o Centro-Oeste parecem estar sendo especialmente afetados, além de Minas Gerais.

A gravidade da situação - sendo o Brasil hoje o segundo país em número de casos no mundo, ficando atrás apenas dos Estados Unidos - certamente tem suas raízes no completo e quase criminoso descaso do governo federal (e alguns governos estaduais e municipais) frente a uma emergência sanitária sem precedentes. $\mathrm{O}$ país poderia ser comparado a uma nau sem rumo, levada ao sabor das ondas, sem uma liderança ou autoridade sanitária responsável que aponte rumos ou, ao menos, demonstre solidariedade para com a população atingida. Isso sem falar em medidas de mitigação da crise econômica gravíssima com resultados sociais assustadores.

Chegar ao ponto em que chegamos sem um ministro da Saúde efetivo, que tome as rédeas da situação, organize os dados sobre contágio e óbitos, orientando as açôes de estados e municípios, é da ordem do impensável. Mas é esta a situação do país. $\mathrm{E}$ a isso se juntam dois fatores agravantes. De um lado, o desmonte do sistema 
público de saúde, vítima de subfinanciamento e descaso governamental que vêm se agravando nos últimos anos. De outro, a desigualdade socioeconômica, à qual se junta um persistente racismo estrutural, que fragiliza uma parcela considerável da população, em especial a população negra e indígena.

Instituiçôes de pesquisa e ensino e associaçôes profissionais estão buscando cobrir o vácuo de organização e orientação. No dia 24 de julho do corrente, a Associação Brasileira de Saúde Coletiva (ABRASCO), em conjunto com outras 12 entidades científicas da Saúde Coletiva e Bioética e o Conselho Nacional de Saúde (CNS), integrantes da Frente pela Vida, apresentou ao Ministério da Saúde e ao Conselho Nacional de Secretários de Saúde (CONASS) o Plano Nacional de Enfrentamento à Covid-19 (cf. ABRASCO, 2020). Por outro lado, movimentos sociais baseados em comunidades carentes estão também se organizando desde o início da epidemia, de modo a fornecer dados, informação, ajuda e acolhimento a quem necessita nas comunidades. Lideranças locais têm propiciado reaçóes e soluções que têm conseguido mitigar fortemente o agravamento da epidemia em favelas de São Paulo, Rio de Janeiro e outras grandes cidades brasileiras (cf. ORTEGA; ORSINI, 2020).

Tendo em vista essa situação de emergência sanitária que impacta tão fortemente todos nós, consideramos importante abrir espaço na revista para reflexôes sobre a pandemia, ainda que menos elaboradas e amadurecidas como se esperaria de um artigo, e que, passando por uma avaliaçáo da editoria e convidados, tivessem sua publicação agilizada.

Juntamo-nos, assim, a outras iniciativas no ca mpo dos estudos sociais e publicamos, no último número da revista, uma série de comentários analíticos sobre a pandemia, que buscaram explorar reflexôes acerca da circulação social do coronavírus e de seu significado político. Neste número trazemos de novo um conjunto de comentários, desta feita tendo como tema o desmonte do Estado que prejudica a capacidade de gestâo e de operação pública do SUS, e que vem se agravando nos últimos anos. A ideia foi refletir sobre como tal desmonte tem impactado de forma trágica sobre a pandemia que agora vivemos.

Acreditamos que o objetivo de trazer contribuiçôes originais para pensar a face sociopolítica, econômica e simbólica da pandemia foi cumprido, mas não deve se esgotar aqui. Uma revista científica tem como finalidade a divulgação da boa ciência. E, como sabemos, sobretudo neste momento, a boa ciência no campo da Saúde Coletiva tem um significado político que nunca é demais ressaltar. 


\section{Referências}

ABRASCO. Entidades apresentam Plano Nacional de Enfrentamento à Covid-19 ao Ministério da Saúde e ao Conass. Rio de Janeiro, 24 jul. 2020. Disponível em: <https://www.abrasco.org. $\mathrm{br} /$ site/noticias/especial-coronavirus/entidades-apresentam-plano-nacional-de-enfrentamentoa-covid-19-ao-ministerio-da-saude-e-ao-conass/50587/> Acesso em: 26 jul. 2020.

ORTEGA, F.; ORSINI, M. Governing COVID-19 without government in Brazil: Ignorance, neoliberal authoritarianism, and the collapse of public health leadership. In: Global Public Health. Disponível em: <https://doi.org/10.1080/17441692.2020.1795223> Acesso em: 25 jul. 2020. 